\title{
Spoken English Training of Winter Olympics Volunteers Based on Production-Oriented Approach
}

\author{
Huijun Fu, Xuwei Li \\ Baoding University, Baoding, China \\ Email: fuhuijun@bdu.edu.cn
}

How to cite this paper: Fu, H. J., \& Li, X. W. (2021). Spoken English Training of Winter Olympics Volunteers Based on Production-Oriented Approach. Open Journal of Modern Linguistics, 11, 327-334. https://doi.org/10.4236/ojml.2021.113026

Received: May 11, 2021

Accepted: May 31, 2021

Published: June 3, 2021

Copyright $\odot 2021$ by author(s) and Scientific Research Publishing Inc. This work is licensed under the Creative Commons Attribution International License (CC BY 4.0).

http://creativecommons.org/licenses/by/4.0/

\section{(c) (i) Open Access}

\begin{abstract}
Spoken English training of volunteers for the 2022 Winter Olympics can promote their English communicative ability, thus better serve the volunteer work. Production-oriented Approach (POA) proposed by professor Wen Qiufang is a new teaching system with Chinese characteristics. The paper provides an overview of POA and analyzes the status quo of spoken English of Winter Olympics volunteers. Then the paper further studies how to apply POA to spoken English training of Winter Olympics volunteers. Through the teaching process of Motivating, Enabling and Assessing, POA can promote volunteers' output of spoken English, and the training effect of spoken English. The study is expected to provide some enlightenment for the spoken English training of Winter Olympics volunteers.
\end{abstract}

\section{Keywords}

The Winter Olympics, Spoken English, Production-Oriented Approach (POA), Volunteers

\section{Introduction}

On Jul. 31, 2015, Beijing was awarded the 2022 Winter Olympics. This is the first time for China to hold the Winter Olympics. On Jan. 20, 2021, President Xi Jinping presided over a meeting on the Beijing 2022 preparations. President Xi (2021) noted that hosting an excellent 2022 Games is a solemn commitment to the international community, and a stronger sense of responsibility, mission and urgency is needed during the preparation work. According to Beijing Organizing Committee for the 2022 Olympic and Paralympic Winter Games (BOCOG), 27,000 Games volunteers will be needed for the Olympic Winter Games and 12,000 for 
the Paralympic Winter Games. Responding to the call of the country, Baoding University will send many qualified volunteers for the Winter Olympics.

As spoken English plays an important role in communication, the volunteers will obtain spoken English training in order to enhance the service quality. Production-oriented Approach (POA) put forward by professor Wen Qiufang is a new foreign language teaching theory with Chinese characteristics. POA can promote the combination of learning and application of spoken English, thus strengthening learners' language communicative ability. After the investigation of the status quo of volunteers' spoken English, the study will focus on applying POA to spoken English training of Winter Olympic volunteers. It is hoped that the study can develop volunteers' spoken English, promote the communication of people throughout the world and ensure the successful holding of the 2022 Winter Olympic Games from the volunteer service perspective.

\section{An Overview of Production-Oriented Approach}

Production-oriented Approach (POA) is a new foreign language teaching system advocated by professor Wen Qiufang. Through an exploration of over ten years, POA was first invented based on Output-driven Hypothesis and Output-driven and Input-enabled Hypothesis, and has get its development after two revisions from the year 2016 to 2018 (Wen, 2018). As a theoretical system, POA involves three parts: teaching principles, teaching hypotheses and teaching process (Wen, 2015). Figure 1 shows the theoretical system.

Teaching principles include Learning-centered Principle, Learning-using Integrated Principle, and Whole-person Education Principle. Different from student-centered concept, Learning-centered Principle emphasizes that all the activities of classroom teaching should serve effective learning. Learning-using Integrated Principle advocates the close combination of input learning and output application, so as to promote the output ability. Whole-person Education Principle indicates college English teaching should serve the all-round development of students, thus achieving the instrumental and humanistic goals of college English teaching.

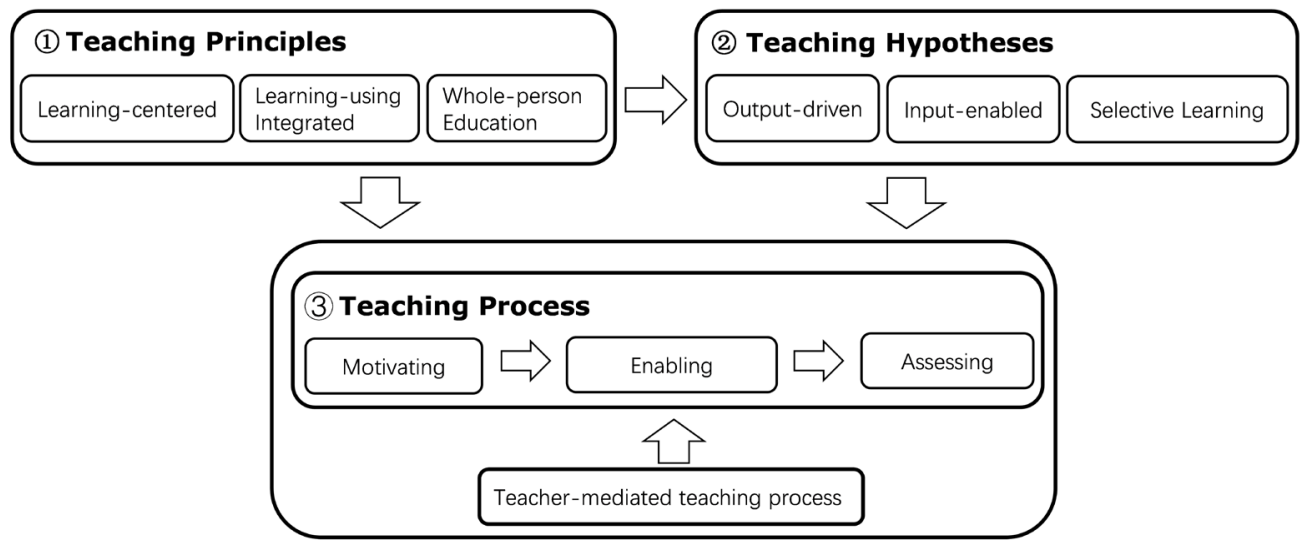

Figure 1. The theoretical system of POA (Wen, 2015). 
Teaching hypotheses include Output-driven Hypothesis, Input-enabled Hypothesis, and Selective Learning Hypothesis. Output-driven Hypothesis is different from the traditional input-output teaching mode. Wen (2015) holds that output driven is both the driving force and the target of language learning, and language teaching should adopt the output-input-output mode. It's because output learning can better activate students' learning enthusiasm than input learning. Input-enabled Hypothesis suggests teachers provide proper input materials to expand students' scope of knowledge. Selective Learning Hypothesis holds that students can select useful input materials to make deep processing, exercising and memorization, thus enhancing the efficacy of learning.

Teaching process involves Motivating, Enabling and Assessing. In the phase of Motivating, teachers provide communication scenarios for students to finish. Students realize the shortage of knowledge and develop the learning desire. Then teachers introduce the teaching objectives and output tasks. In the phase of Enabling, teachers first describe the output tasks. Then students turn to selective learning, which generally involves ideas, language and discourse structure. Teachers give effective guidance and examination. After that, students practice output, while teachers continue giving effective guidance and examining the output results. As to Assessing, it involves the assessment in the Enabling phase and the assessment after students finishing extracurricular exercises. Output of the latter covers review output and transfer output. The whole teaching process is teacher-mediated, and teachers play the roles of guiding, designing and scaffolding.

Through two revisions, POA has developed into a more scientific and comprehensive theoretical system. Figure 2 shows the second revised version of theoretical system of POA. In this version, Cultural Communication Principle is added, and the principle of Whole-person Education is replaced by the principle

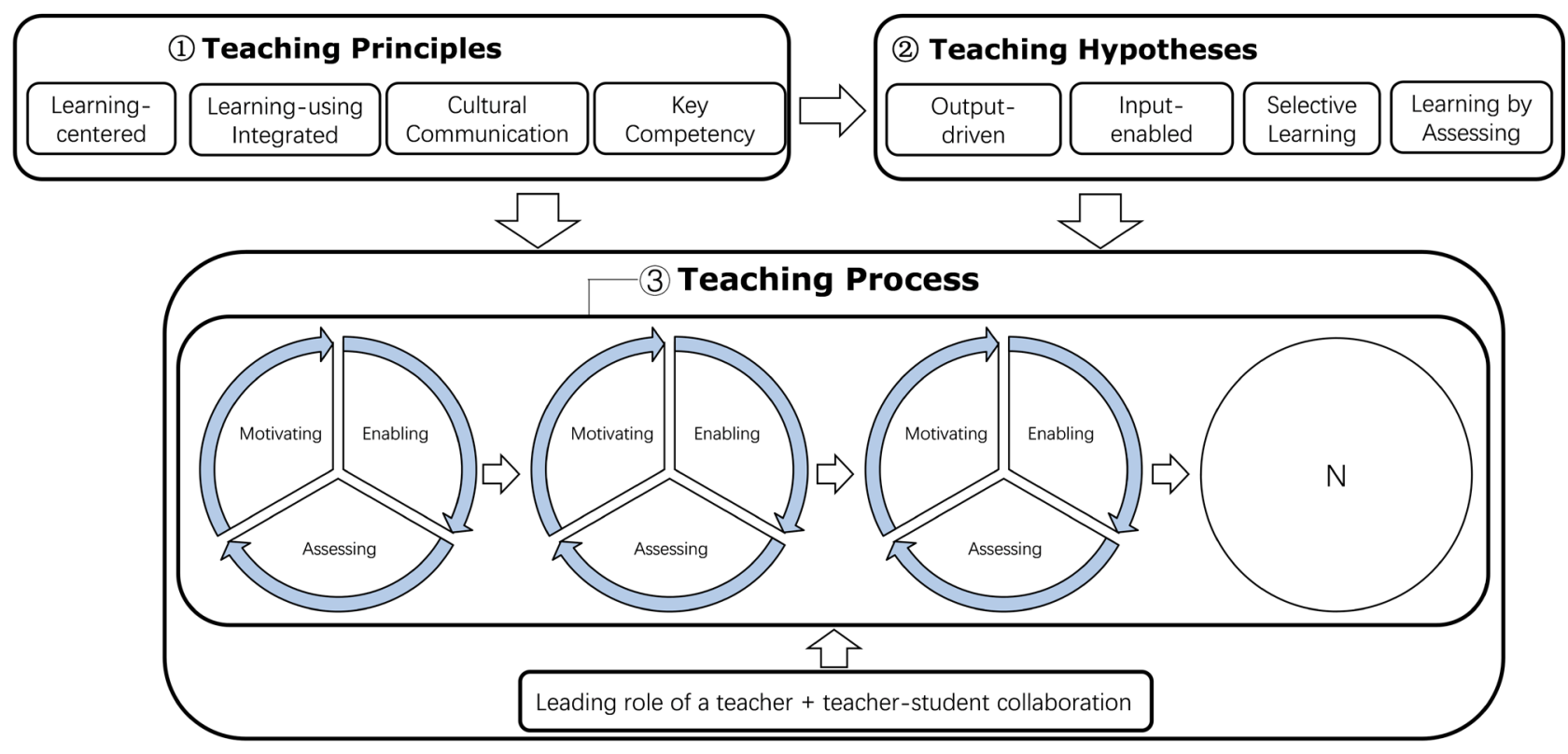

Figure 2. The second revised version of theoretical system of POA (Wen, 2018). 
of Key Competency, which focuses on the educational objectives and varies according to different teaching objects. Learning by Assessing Hypothesis aims to break the boundary between learning and assessing through teacher-student collaborative assessment (Wen, 2016). Meanwhile, teacher-student collaboration also receives attention. As to teaching process, it is optimized into several circulating chains, each of which involves Motivating, Enabling and Assessing. The realization of each output objective will contribute to the realization of overall objective output. On the whole, POA can promote language learners' key competencies, achieve better teaching effect, and improve the teaching quality.

\section{The Status Quo of Spoken English of Winter Olympics Volunteers}

The selection of Winter Olympics volunteers in Baoding University is open to freshmen and sophomores of all majors. Most of the students have actively signed up for the selection activity. Finally, altogether 124 students were successfully selected and will assume the volunteer work for the 2022 Winter Olympics. Among those volunteers, 25 of them major in English or Business English, and the other 99 volunteers are students of non-English majors. In order to investigate the status quo of spoken English of Winter Olympics volunteers, the research group designed the questionnaire and the interview. Altogether 80 Winter Olympics volunteers of Baoding University were selected randomly to complete the questionnaire. To ensure the objectivity of the questionnaire, all the respondents were told the purpose of the questionnaire. Totally, 80 copies of questionnaire were recollected and 76 copies were valid. Meanwhile, 15 college English teachers joined the interview. Results of the investigation show the status quo of spoken English of Winter Olympics volunteers.

1) Prior English knowledge

All of the volunteers have accepted at least six years of English learning. They have acquired basic spoken English expressions. Their reading and writing levels are relatively better than their spoken English level. Only 38 respondents have passed College English Test-4 (CET-4), that's maybe because all the freshmen are not allowed to take CET-4 during the first semester and they hadn't taken it by the time the questionnaire was conducted. Besides, some sophomores also didn't pass CET-4. As most respondents are non-English majors, their prior English knowledge is quite limited. All the respondents agree that they sometimes cannot flexibly select proper words to express their opinions and they sometimes make grammar mistakes. 71 respondents are not satisfied with their pronunciation and intonation. Those problems will directly affect the clear and fluent communication with foreigners.

2) Learning methods

63 respondents hold that they mainly receive mechanic spoken English practice from the textbook, such as listening to some words or sentences and then repeating. Their learning of spoken English mainly focused on the class. However, they don't have enough time in the class to communicate with others and 
they lack interaction. Only 18 respondents attend the English Corner regularly. 33 respondents love to sing English songs. 28 respondents sometimes watch original English films. Only 6 respondents have participated in English speech contests and received specialized training. Most respondents have little opportunities to communicate with foreigners and don't pay enough attention to cultural differences in spoken English learning. As can be seen from the above data, many volunteers are not equipped with varied methods to learn spoken English, and their learning methods are relatively monotonous and dull.

3) Learning ability

68 respondents hold that they are aware of making mistakes and they can correct the mistakes immediately while practicing spoken English. However, only 27 respondents think that they can correct errors in the spoken English. It is obvious that their ability to correct errors in spoken English learning is low, which is related to their limited English proficiency. At the same time, most respondents agree that they seldom actively reflect on how they can improve their English expressions and they lack self-evaluation in spoken English learning. Moreover, 54 respondents hold they seldom spare time to practice spoken English except finishing the teacher's oral English assignment. As they mainly focus on English reading and writing practice, the study of spoken English is quite weak. They lack the autonomous learning of spoken English, so their autonomous learning ability is expected to get promoted.

4) Affective attitude

73 respondents have no confidence in spoken English. They feel more or less anxious to express their ideas, and their psychological quality is not strong. Some respondents feel nervous when they are talking in English. Especially when they make mistakes or errors, they will feel ashamed and even develop fears of spoken English. This is not helpful to improve the self-efficacy. Besides, 26 respondents have no interest in practicing spoken English, as they never take the initiative to express their opinions in English in the class. They are almost dummy English learners. Affective attitude plays an important role in promoting spoken English ability of Winter Olympics volunteers, thus it cannot be ignored.

Based on the data, it can be seen that the result of the investigation is not satisfactory. Although all of the volunteers have passed the spoken English test in the selection stage, there are still some problems in their spoken English, which is expected to get promoted, especially for non-English major volunteers.

\section{Applying POA to Spoken English Training of Winter Olympics Volunteers}

Based on the status quo of spoken English of Winter Olympics volunteers, researchers make an attempt to apply POA to their spoken English training aiming to promote their spoken English ability and help them become competent for future volunteer work. The detailed teaching design is as follows.

First, sticking to the learning-centered principle, the teacher constructs the 
motivating part to activate the volunteers' learning motivation and encourage them to make output attempts. The teacher should first assign an output task by creating a real communicative situation. For example, suppose the Winter Olympics volunteers work in the Food and Beverage Department of a hotel. The teacher introduces the situation to volunteers, then tell them the output task is to finish the communication about dining at the restaurant. Considering the volunteers' limited prior English knowledge and different English proficiency, the teacher decomposes the output task into two parts, and selects some comprehensible input materials such as pictures and hints of difficult words. Part one is to guess the expressions of Chinese and Western food based on pictures. Part two is a thinking task by presenting a picture, which shows a waiter is welcoming the guests. Volunteers are required to tell the reasons of the waiter's behavior, and also to discuss the importance of the job, which aim to develop the key competencies of spoken English communication and their love to the volunteer work. The volunteers are suggested to work in groups to finish the task cooperatively, and list the difficulties in the output attempt. They will realize the shortage of spoken English knowledge as well as skills. Meanwhile, in order to overcome volunteers' fear of speaking in English, the teacher should give them constant encouragement and appropriate feedback so as to cultivate their self-confidence and stimulate their desire to practice spoken English, which will prepare well for the subsequent spoken English learning.

Second, in the enabling phase, learning and using should be integrated, and the relationship of the teacher and volunteers should be coordinated well. As Professor Wen put it, "In the whole teaching process, teachers play the leading role as they are the designer, organizer, leader and director of classroom teaching (Wen, 2017)." However, this is not the negation of learners' principal part, because highlighting teachers' leading function can realize the maximum effectiveness of learning. In this phase, the teacher further explains the output task and provides more related input materials for students to finish the output task. For instance, the teacher plays the scaffolding role and provides materials about Welcoming and seating guests, and Taking orders. By this way, volunteers' learning becomes more targeted, meanwhile, they can learn efficiently in the limited class time. Volunteers' principal part should not be neglected too. They first finish the enabling of content by reading the two materials. Besides, they can finish the enabling of language forms through autonomous learning and cooperative learning to the materials. Some exercises are provided, such as filling in the blanks, sentence making, describing pictures. They can also collaborate with the teacher on the difficult exercise. In addition, volunteers will finish the enabling of discourse structure. Led by the teacher, they listen to the audio and follow the audio through role play. Then they will finish the enabling of communicative skills through situational practice. The teacher will give necessary guidance on pronunciation, intonation, pauses over sense groups, stress, liaison, strategies of language expression, etc. POA advocates the teaching principle of 
Cultural Communication, which focuses on teaching content and aims to correctly deal with the relationship between the culture of target language and the native culture (Wen, 2018). So the teacher should pay attention to the analyses of cultural differences. In this phase, the output target can also be decomposed into smaller ones, which will be easier for volunteers to realize. There are also many ways of enabling volunteers to output. For example, in order to effectively enable them to communicate in English, the teacher tries to convert the classroom into a room for performance or interview, so that their enthusiasm of spoken English learning can get fully mobilized. In the enabling phase, volunteers are also guided to grasp various methods of spoken English learning. Finally, volunteers integrate what they have learned from the input materials into the output of spoken English, thus making the output more efficient. This will be beneficial in improving the spoken English ability of the Winter Olympics volunteers and enhancing the training effect in a short time.

Third, from the perspective of time, assessment of spoken English training can take two forms. One is the prompt assessment to the small output task of volunteers' spoken English, while the other is the delayed assessment. Assessment is regarded as the strengthening and deepening of learning. As POA emphasized the learning-centered concept, no matter what type of assessment is, the aim of it is to promote the happening of learning, so as to optimize the learning effect. In the delayed assessment, volunteers first post their spoken English outputs to the learning platform before class, which are in the form of audio or video. The teacher picks out the typical homework from the platform, and designs the key points of assessment. In class, assessing criteria are further discussed and worked out through the teacher's lead and teacher-student collaboration. Based on the assessing criteria, volunteers first make self-assessment, then make peer assessment through group discussions on the homework. Through the discussion, they can discover inappropriate expressions, and mistakes of pronunciation, intonation and so on. At the same time, they can make corresponding reflection on how to improve their spoken English. If platform permits, automated assessment is quite useful. Besides, teacher-student collaborative assessment is encouraged. The teacher will give proper feedback including the strengths and weaknesses. The former aims to increase volunteers' spoken English learning interest, thus getting them more actively involved in the spoken English training. The latter aims to reveal the problems which volunteers tend to neglect in the peer assessment, for example, the improper body language, speed of speech, eye contact, etc. After assessing, the output results of spoken English will be modified and upload again to the learning platform for sharing. Therefore, the assessing part can promote the training effect of volunteers' spoken English, leading them to become more competent in spoken English communication.

\section{Conclusion}

Now the preparation for the 2022 Winter Olympics has entered its final stretch. The Winter Olympics will provide a platform for volunteers to show the spiri- 
tual outlook of Chinese people. The quality of volunteer service not only concerns the national image, but also ensures the successful holding of the Winter Olympics. Spoken English ability of volunteers is very important for improving the quality of service. In view of the status quo of spoken English of Winter Olympics volunteers, spoken English training is quite necessary and urgent. POA is a new teaching mode, which adopts the teaching process of Motivating, Enabling and Assessing. Spoken English training of Winter Olympics volunteers based on POA can increase volunteers' spoken English interest, activate their willingness to practice spoken English, and promote their cross-cultural communicative competence. Therefore, the study has important social and practical implications. It is hoped that the study can provide some insight into volunteers' spoken English training. Meanwhile, in order to better serve the Winter Olympics, the training contents of spoken English should be divided into different parts based on the volunteer work. How to effectively apply POA to each training content still deserves further study.

\section{Conflicts of Interest}

The authors declare no conflicts of interest regarding the publication of this paper.

\section{References}

Wen, Q. F. (2015). Developing a Theoretical System of the Production-Oriented Approach in Language Teaching. Foreign Language Teaching and Research, 4, 547-558+640.

Wen, Q. F. (2016). Teacher-Student Collaborative Assessment: An innovative Assessment Method for the Production-Oriented Approach. Foreign Language World, 5, 37-43.

Wen, Q. F. (2017). Chinese Features Displayed in the Production-Oriented Approach. Modern Foreign Languages, 3, 348-358+438.

Wen, Q. F. (2018). Production-Oriented Approach in Teaching Chinese as a Second Language. Chinese Teaching in the World, 3, 387-400.

Xi, J. P. (2021). Speech over a Meeting on the Beijing 2022 Preparations. http://www.gov.cn/xinwen/2021-01/20/content_5581375.htm 